\title{
UMA DISCUSSÃO SOBRE A SUBSTITUIÇÃO DA ECONOMIA DO CRIME
}

\section{ARTIGO DE REVISÃo}

CARVALHO, Rogério Galvão de ${ }^{1}$, LEAL, Cicero Pereira ${ }^{2}$

CARVALHO, Rogério Galvão de. LEAL, Cicero Pereira. Uma discussão sobre a substituição da economia do crime. Revista Científica Multidisciplinar Núcleo do Conhecimento. Ano. 06, Ed. 09, Vol. 06, pp. 141-152. Setembro 2021. ISSN: 24480959, Link de acesso: https://www.nucleodoconhecimento.com.br/cienciassociais/economia-do-crime, DOI: 10.32749/nucleodoconhecimento.com.br/cienciassociais/economia-do-crime

\section{RESUMO}

Dado a existência da economia (indústria) criminosa, que recruta, seleciona, treina e capacita agentes, conforme se observa em algumas regiões do Brasil, além de contribuir para níveis altos de criminalidade nessas regiões, verificou-se a necessidade da elaboração de uma política pública assertiva, a fim de minimizar os impactos negativos dessa indústria para a sociedade. Dessa forma, este artigo apresenta uma contribuição para a discussão da possibilidade de substituição da economia (indústria) do crime pela economia (indústria) legalmente constituída, uma política pública customizada que poderá contribuir com o desenvolvimento regional e combate ao crime ao mesmo tempo. Com uma revisão da literatura de economia do crime, que proporciona compreender a ideia central dessa proposta de discussão para avaliação do processo de substituição. A questão norteadora da pesquisa é "porque os governos subnacionais do Brasil não levam em conta a substituição da

\footnotetext{
${ }^{1}$ Doutorando em Ciencias Empresariais, na Universidad de Ciencias Epresariales y Sociales, de Buenos Aires, UCES, Mestre em Economia pela Universidade Católica de Brasília UCB, especialista em Direito Público pela Universidade Estácio de Sá, Bacharel em Economia pelo Centro Universitário de Brasília CEUB. ORCID: https://orcid.org/0000-0002-7461-4609.

${ }^{2}$ Doutorando em Ciências Sociais, na UNISINOS, Mestre em Economia pela UnB, Bacharel em Economia pela UnB. ORCID: https://orcid.org/0000-0003-4082-295X
}

RC: 97949

Disponível em: https://www.nucleodoconhecimento.com.br/cienciassociais/economia-do-crime 
economia criminosa pela economia legalmente constituída, como política pública?" o artigo pretende promover um debate que possibilite a transformação da economia regional com o incentivo do desenvolvimento da economia local aproveitando a vocação econômica, e os recursos advindos do confisco e transferência da atividade criminosa, para promover a substituição da "economia criminosa" pela "economia legalmente constituída", incluindo as atividades não tradicionais como: economia criativa, solidária e circular. $\mathrm{O}$ artigo tem como objetivo a proposição de um debate sobre a possibilidade de substituição da economia "do crime" pela economia "legalmente constituída", como alternativa auxiliar para o combate ao crime e, simultaneamente o fomento do desenvolvimento econômico nas regiões violentas do Brasil. A metodologia foi uma análise teórica com fulcro na literatura de economia do crime e na correlação negativa entre 0 desenvolvimento econômico e a criminalidade conforme restou demonstrado no transcurso da pesquisa.

Palavras-chave: Economia do crime, Desenvolvimento Econômico, Economia Regional.

\section{INTRODUÇÃO}

Esse artigo pretende, por intermédio da comparação dos níveis de violência e do grau de desenvolvimento econômico de uma região, estabelecer bases concretas para a discussão e proposição de um capítulo importante na política industrial diferenciada, para o Brasil. A partir da identificação e mapeamento tanto da vocação econômica da região, quanto de sua mancha criminal.

É sabido que há uma correlação negativa muito forte entre desenvolvimento econômico, especialmente a industrialização (que é apontada como o processo mais bem sucedido na geração de emprego, renda e sustentabilidade econômica das civilizações humanas recentes) com os níveis de criminalidade. Levando-se em conta ainda a literatura sobre economia do crime, que contextualiza a ação criminosa como uma ação econômica qualquer, onde as ações dos agentes respondem por incentivos ou punições. 
A referida proposta consiste numa discussão sobre a política pública de substituição da economia (ou indústria) do crime pela economia (indústria) legalmente constituída, como alternativa complementar no auxílio ao combate da criminalidade, em especial nas regiões mais violentas, e simultaneamente 0 fomento do desenvolvimento econômico regional.

A partir da delimitação territorial da mancha criminal, os policymakers poderiam investir na substituição paulatina da indústria do crime: (1) tráfico de drogas, entorpecentes e seres humanos; (2) furtos e roubos; (3) descaminho e contrabando; (4) falsificação; e etc. por fortes incentivos (fiscais, creditícios e até econômicos) governamentais nos arranjos produtivos locais, ou nos potenciais econômicos da região, para a absorção dos fatores de produção (ociosos) oriundos do combate à economia (indústria) criminosa. A referida proposta seria a discussão com fulcro na ideia de que a conduta criminosa, com raras exceções, se dá por conta de incentivos aos agentes, conforme preconiza a teoria econômica, na parte de análise econômica do direito.

À medida que houvesse o confisco ou transferência, paulatina e constante, dos recursos (financeiros, logísticos, de Tecnologia e de pessoal) daquela indústria (criminosa) ao Estado (pelas ações policiais ou decisões judiciais) o processo se daria, de forma paulatina, recursiva e crescente. O governo, por intermédio de incentivos (fiscais, creditícios e até econômico), fomentaria a atividade econômica legalmente constituída naquela região, com a meta de desenvolvê-la nos seguintes pontos: (i) educação (básica, fundamental, técnica e superior); (ii) saúde (baixa, média e alta complexidade); (iii) segurança pública; (iv) industrialização e os investimentos nos arranjos produtivos locais ou na vocação econômica da região.

Em suma, a proposta pretende incentivar discussões teóricas e empíricas com vistas a diminuir a criminalidade, se apropriando do parque industrial do crime, transferindo os recursos (por intermédio das ações, projetos e programas governamentais) para a economia legalmente constituída, inserindo no processo decisório também o setor produtivo e a sociedade civil com base nos preceitos da 
Teoria do Crime, associada a correlação negativa entre desenvolvimento econômico e os níveis de criminalidade.

\section{REVISÃO TEÓRICA}

\section{a) Teorias sobre as causas da criminalidade}

As investigações científicas sobre a criminalidade apontavam como motivação inicial para que o indivíduo cometesse o crime dois eixos: (1) motivação pessoal; e (2) contexto social. Historicamente a sociologia detinha os debates sobre o tema dando contribuições expressivas sobre o assunto. Porém, a partir da segunda metade do século XX o tema passou a fazer parte das discussões da economia.

De acordo com Cressey (1968) a teoria que tentasse mensurar, descrever ou explicar o comportamento do criminoso, deveria analisar como tais comportamentos se distribuem e se deslocam espacial e temporalmente.

Cano e Soares (2002) apontaram cinco grupos de teorias distintas para avaliar o tema: a) teorias que tratam o crime sob a ótica de patologia individual; b) teorias que consideram o crime como subproduto de um sistema social perverso ou deficiente; c) teorias que entendem o crime como uma consequência da perda de controle e da desorganização social na sociedade moderna; d) correntes que defendem explicações do crime em função de fatores situacionais ou de oportunidades e e) teorias centradas no homo economicus, isto é, no crime como uma atividade racional de maximização do lucro a abordagem econômica de Gary Becker (1968), que é a que nos interessa nesse artigo.

De acordo com Shaefer e Shikida (2001) a chamada Teoria Econômica do Crime, iniciada por Gary Becker, tem como premissa que a tomada de decisão dos indivíduos em relação a cometer crimes que visem lucros financeiros é uma atividade ou setor da economia, como outro qualquer. 
Segundo Britto (1999), a hipótese de Gary Becker, prevê que um aumento na probabilidade de punição efetiva de um cidadão, deve reduzir substancialmente o potencial número de delitos que ele venha a cometer. Tal premissa, estabelece que o indivíduo que comete um crime de cunho econômico pode ser considerado um "empresário" de qualquer ramo de atividade econômica, seu objetivo primordial é a maximização do lucro.

Ainda de acordo com esse autor, nesse "mercado" existe um grande risco daquele individuo sofrer algum tipo de sanção (multa ou prisão) ou de morrer. Becker (1968) parte do pressuposto de que o indivíduo criminoso, conforme seu grau de aversão ao risco decide quanto de seu tempo alocar entre uma atividade econômica legal ou ilegal. Assim, se sua utilidade esperada ao cometer um ato delituoso for maior que a utilidade que poderia vir a obter no mercado legal, ele opta por cometer o delito.

De acordo com Scotti (2007), outra questão importante, com base nas hipóteses da Teoria Econômica do Crime (de Gary Becker), o indivíduo que comete crimes para obter vantagem financeira pode ser considerado como 0 tradicional Homo Economicus, que se guia unicamente pela busca da maximização de sua utilidade esperada levando em conta todas as informações disponíveis.

De acordo com Halicioglu (2012), altas taxas de desemprego podem afetar as taxas de criminalidade. $\mathrm{O}$ desemprego pode atuar como agente motivador dos crimes por conta da uma piora da situação econômica dos indivíduos, que tem incentivo de cometê-los para manter o padrão de consumo observado antes do aumento do desemprego.

Além disso, de acordo com Franco (2016), as contribuições internacionais à teoria do crime têm aumentado nas últimas décadas, por meio de investigações tanto com dados de cross section como análise de séries temporais (WOLPIN, 1978; CRAIG, 1987; TRUMBULL, 1989; ZHANG, 1997, entre outros) ou por intermédio de estimações com dados em painel (WOLPIN, 1980; CORNWELL e TRUMBULL, 1994; entre outros). 
No transcurso dessa revisão teórica, apresenta-se alguns dos resultados obtidos, por uma questão eletiva dos autores, os mais relevantes estudos sobre abordagem para corroborar a discussão da substituição da economia do crime pela economia legalmente constituída.

\section{b) Abordagem Econômica do Crime}

Segundo Neto (2006), a abordagem econômica tem como foco o indivíduo que toma decisões, ou seja, a ênfase está nas escolhas feitas pelo agente econômico. A essência é a de que para cometer o crime, o agente econômico compara os custos e os benefícios envolvidos no ato. Em suma, no processo decisório, a avaliação será se o retorno líquido da ação criminosa é maior que retorno líquido de ação similar legítima, isto é, se o benefício conquistado pelo crime for maior que o adquirido por vias legais (trabalho, empréstimo etc.).

As predições iniciais nesse sentido, na qual a ciência econômica começa a avaliar de forma efetiva a economia do crime, foram realizadas por Becker (1968), que trata como exceção os psicopatas e assume que a ação criminosa está associada a estímulos previsíveis e racionais, cuja equação está relacionada a qualquer outra atividade econômica: (1) custos e retornos; (2) (in)certeza de punição.

O modelo do referido autor (Rational Criminal Model - RCM) preconiza que devem ser observados os riscos e os altos retornos esperados:

$E[u]=p U(Y-f)+(1-p) U(Y)$

Onde: U (.) é a função de utilidade do indivíduo; (p) é a probabilidade de condenação; $(Y)$ resultado obtido com o crime; (f) multas e punições.

Para Neto (2006), Gary Becker, comprova matematicamente que é negativa a relação entre a probabilidade de ser condenado (p) e as multas e punições (f), o que, no fim das contas, gera incentivo ao indivíduo para a conduta criminosa. 
Para Posner (1982), já que a abordagem econômica demonstra ser possível manter um comportamento racional ainda que desviante de normas sociais estabelecidas. Então, as multas ou penas, em vista do desvio de conduta, deveriam partir da lógica microeconômica, isto é, aumento do custo de se engajar numa atividade ilegal, pela maior dosagem da multa e da pena e pela maior certeza da aplicação. Pois, dessa forma, induzirá cada vez mais indivíduos a reduzir o envolvimento em tais atividades. Só continuarem aqueles que ainda percebessem os benefícios excedendo os custos mais elevados.

Além disso, levando-se em conta os incentivos (ou desincentivos) econômicos para a prática criminosa, foram realizados vários trabalhos empíricos sobre políticas públicas combinando investimentos em segurança pública e aumento do desenvolvimento econômico (BITU, 2008; CERQUEIRA E LOBÃO, 2002; COELHO, 1988; e PAIXÃO, 1988) observando séries históricas, corroborando a ideia de que a atividade criminosa se reduz quando a atividade econômica legalmente constituída aumenta, isto é, quando há desenvolvimento econômico na região analisada.

Faz-se necessário registrar que nem todos concordam em gênero, número e grau com as ideias de Gary Becker. Gibbons (1982), por exemplo, assevera que a decisão de cometer crimes nem sempre segue o raciocínio proposto. De acordo com o autor, a decisão de cometer crime é muito mais ligada ao contexto social, então seria uma decisão normativa.

\section{c) A Política Pública de Substituição}

De acordo com Carvalho; Leal e Souza (2021) uma política pública de desenvolvimento econômico deve ter como premissa a transformação socioeconômica de uma região, criando condições sustentáveis de geração de emprego, aumento e distribuição de renda, a partir da identificação, mapeamento e georreferenciamento da vocação econômica. De acordo com Pitangui et al. (2019), A investigação do comportamento da vocação econômica possibilita o planejamento e contribui para o desenvolvimento econômico regional. 
Para Carvalho e Leal (2021) é de suma importância a escolha de bons de indicadores na fase de acompanhamento (monitoramento, avaliação e ajuste) da execução das políticas públicas, para se obter resultados mais assertivos, com relação à medição do desempenho das políticas públicas da agenda central do governo, com isso, é possível inferir que o processo de substituição da indústria criminosa pela industrialização local deve envolver "uma força tarefa", sistemática, recursiva e sistêmica, entre órgãos governamentais de segurança pública, de educação, de qualificação profissional, de desenvolvimento econômico, saúde e outros; do setor produtivo (Sistema S, Federação da Indústria, Associação Comercial, Universidades, Faculdades e Institutos de Pesquisa e outros) e da Sociedade Civil (CUFA, OAB e conselhos profissionais, comunidade religiosa, OSCIPS e outros) com intuito de integrar o modelo de desenvolvimento econômico com foco em industrialização e investimentos produtivos (da economia legalmente constituída). Talvez por tudo isso, haja pouco interesse em incluir um capítulo sobre a substituição da "economia do crime" na elaboração, formulação e implementação dessa política pública.

A discussão teórica e empírica para esse tema, proposta nesse artigo, tem como premissa que se leve em conta as hipóteses da teoria econômica do crime acerca da relação entre os incentivos econômicos e ação criminosa, que sejam observados também os dados: (1) tanto sobre homicídios, no atlas da violência, produzido pelo Instituto de Pesquisa Econômica Aplicada - IPEA; (2) quanto o ranking da participação industrial produzido pela (CNI) Confederação Nacional da Indústria; e (3) como o índice de desenvolvimento humano - IDH (dados de 2017).

Então, verifica-se, em regra, que quanto melhor o IDH, menos violento é a unidade da federação, por exemplo os Estados: São Paulo (SP), Santa Catarina (SC), Minas Gerais (MG) e Paraná (PR) detém os melhores IDHs e são os menos violentos. Por outro lado, os estados brasileiros com piores IDHs, em regra, também são os mais violentos: Bahia (BA), Alagoas ( $A L)$, Pará (PA) e Sergipe (SE). 
Da mesma forma, quanto maior foi a participação industrial do estado brasileiro no PIB, maior foi o registro de IDH. E, simultaneamente, registrou-se menos homicídios para os referidos estados brasileiros. Exemplos: as maiores participações na indústria de acordo com os dados da CNI, São Paulo (SP), Santa Catarina (SC), Minas Gerais (MG) e Paraná (PR) coincidem com os IDHs mais altos.

Dessa forma, observa-se que as correlações inversamente proporcionais de (1) alto IDH com (2) baixos registros de criminalidade e de (3) do elevado grau de participação industrial no PIB brasileiro, com (1) os melhores IDHs. Então, a proposta do artigo seria uma política pública de substituição da economia (indústria) do crime, pela economia (indústria) legalmente constituída.

A proposta tem como base também a literatura de economia do crime, trazida no capítulo do referencial teórico, que deixa clara que o criminoso obedece aos mesmos preceitos de incentivos e punições da teoria econômica tradicional, ou seja, avaliando riscos e retornos acerca das ações.

\section{CONCLUSÃO}

Essa investigação visou promover um debate a partir da avaliação teórica sobre a ideia do combate, com inteligência, às grandes estruturas criminosas de negócio, com a finalidade substitui-las pela economia legalmente constituída com base tanto nas hipóteses da teoria econômica do crime, quanto na correlação negativa entre desenvolvimento econômico e criminalidade. A a ideia central da discussão é a proposta da transferência, paulatina e constante, dos recursos (financeiros, logísticos, de Tecnologia e de pessoal) daquela indústria (à medida que for transferida) ao Estado (pelas ações policiais ou judiciais) e, posteriormente, para incentivos (fiscais, creditícios e até econômico) para o fomento da legalmente constituída com meta de desenvolver: (i) educação (básica, fundamental, técnica e superior); (ii) saúde (baixa, média e alta complexidade); (iii) segurança pública; (iv) industrialização e os investimentos nos arranjos produtivos locais ou na vocação econômica da região.

RC: 97949

Disponível em: https://www.nucleodoconhecimento.com.br/cienciassociais/economia-do-crime 
A sugestão para as pesquisas com relação ao tema deveriam ter como ponto de partida a coleta, a organização, a sistematização, e o compartilhamento inteligente dos dados precisos sobre: (a) a identificação, mapeamento e georreferenciamento da indústria do crime (narcotráfico, tráfico de mulheres, roubo, furto etc.); (b) a localização das manchas criminais (em especial da produção, armazenamento, estocagem e distribuição); e (c) o processo de seleção, recrutamento, capacitação e qualificação da mão de obra (criminosa) de crianças, jovens e adultos.

Portanto, as discussões sobre o processo de substituição da indústria criminosa pela industrialização local devem envolver uma força tarefa (setor produtivo, governo e sociedade civil), com intuito de integrar o modelo de desenvolvimento econômico com foco em industrialização e investimentos produtivos (da economia legalmente constituída).

Outro ponto desse debate é o desafio de substituir (recursiva e paulatinamente) a atividade econômica criminosa, bem-sucedida do ponto de vista de eficiência, mas danosa à sociedade, pela atividade econômica relacionada a vocação econômica da região com participação dos stakeholders. Nesse caso, a participação do governo, da sociedade civil, e de representantes do setor produtivo, nessa empreitada é fundamental para o sucesso.

\section{REFERÊNCIAS}

BECKER, G. S. Crime and punishment: an economic approach. Journal of Political Economy. V. 76, ํo 01, 1968, p. $69-217$.

BECKER, Gary. S. 1968. Crime and Punishment: An Economic Approach. Journal of Political Economy. Reprinted in Chicago Studies in Political Economy, edited by G.J.Stigler. Chicago and London: The University of Chicago Press, 1988.

BITU, G. B. T. Análise dos principais determinantes da criminalidade no Brasil: 2001 - 2005. Universidade Federal do Ceará. Curso de Pós-graduação em Economia CAEN, Fortaleza, 2008.

RC: 97949

Disponível em: https://www.nucleodoconhecimento.com.br/cienciassociais/economia-do-crime 
BRITTO, Tatiana A. Desemprego e crime: uma análise de séries de tempo para o Distrito Federal: 1992 a 1996. Brasília: Dissertação (Mestrado), 46 p. Departamento de Economia - universidade de Brasília, 1999.

CANO, I., SOARES, G. D. As teorias sobre as causas da criminalidade. Rio de Janeiro: IPEA, 2002, mimeo.

CARVALHO, Rogério Galvão de. LEAL, Cícero Pereira. A Importância Da Escolha De Indicadores Para Avaliação Eficiente De Políticas Públicas. Revista Científica Multidisciplinar Núcleo do Conhecimento. Ano 06, Ed. 04, Vol. 09, pp. 213-221. Abril de 2021.

CARVALHO, R. G. et al. Política pública de atração de investimentos em Brasília: erros e acertos. Revista Científica Multidisciplinar Núcleo do Conhecimento. Ano 06, Ed. 02, Vol. 01, pp. 21-59. fevereiro de 2021.

CERQUEIRA, D. R. C., LOBÃO, W. A. J. L. Condicionantes sociais, poder de polícia e o setor de produção criminal. IPEA, 2002, mimeo.

COELHO, E. C. A criminalidade urbana violenta. Dados. Revista de Ciências Sociais, Rio de Janeiro: luperj, 1988.

CRAIG, S. G. (1987) The Deterrent Impact of Police: An Examination of a Locally Provided Public Service. Journal of Urban Economics. v.21, p.298-311, 1987.

CRESSEY, D. P. Crime: causes of crime in International Encyclopedia of The Social Sciences, v. 3. The Macmillian Company \& The Free Press Ed. (David L. Sills ed.), 1968.

CORNWELL, C.; TRUMBULL, W. N. (1994) Estimating the Economic Model of Crime with Panel Data. The Review of Economics and Statistics. v.76, n.2, p. 360-366, maio 1994. 
FAJNZYLBER, P. (2002). "What causes violent crime?" European Economic Review 46(7): 1323-57.

FAJNZYLBER, P.; ARAUJO JUNIOR, A. F. (2001). Violência e criminalidade. In Lisboa, M. B. \& Menezes Filho, N. A., editores, Microeconomia e Sociedade no Brasil, p. 333- 394. Contra Capa, Rio de Janeiro.

FAJNZYLBER, P., LEDERMAN, D., LOAYZA, N. (1998) Determinants of Crime Rates in Latin America and the World: An Empirical Assessment. Washington, DC: World Bank, World Bank Latin American and Caribbean Studies, 1998.

FRANCO, Cleiton. Revisão de Literatura e Evidencias Empíricas Sobre Economia do Crime. Revista UNEMAT de Contabilidade, Volume 5, Número 9, julho de 2016.

FURTADO, Giovanna Maia. Aplicação da economia do crime no Brasil. São Paulo, 2007. 79 f. Dissertação (Mestrado) - Faculdade Ibmec São Paulo, 2007.

GIBBONS, T. (1982). The utility of economic analysis of crime. International Review of Law and Economics 2 (2): 173-192.

HALICIOGLU, F. Temporal causality and the dynamics of crime in Turkey. International Journal of Social Economics, v. 39, p. 704 - 720, 2012.

LÖSCH, A. The economics of location. New Haven, Yale University. 1954.

NETO, Giácomo Balbinotto. Teoria Econômica do Crime. UFRGS/PPGE, 2006

PAIXÃO, A. L. Crime, controle social e consolidação da democracia. In: REIS \& O’DONNELL (eds.). A democracia no Brasil. Vértice: São Paulo, 1988.

PITANGUI, C.P., TRUZZI, O. M. S., \& BARBOSA, A. S. Arranjos produtivos locais: uma análise baseada na participação das organizações locais para o desenvolvimento. Gestão \& Produção, 2019. 26(2), e2579. https://doi.org/10.1590/0104-530X-2579-19 
POSNER, Richard A. The Economics of Justice. Cambridge: Harvard University Press, 1982.

SCHAEFER, Gilberto; SHIKIDA, Peri A.F. Economia do crime: elementos teóricos e evidências empíricas. Revista de Análise Econômica/UFRGS, edição 36, ano 19, setembro de 2001.

SCOTTI, Ricardo Jefferson. Finanças comportamentais no Brasil. São Paulo, FAAP, 2007, 70p.

TRUMBULL, W. N. (1989). Estimations of the Economic Model of Crime Using Aggregate and Individual Level Data. Southern Economic Journal. v.56, p.423-439, 1989.

WOLPIN, K. (1978). An Economic Analysis of Crime and Punishment in England and Wales, 1894-1967. Journal of Political Economy. v.86, p.815-840, 1978.

. (1980) A Time-Series-Cross Section Analysis of International Variation in Crime and Punishment. The Review of Economics and Statistics. vol.62, p.417-423, 1980.

ZHANG, J. (1997) The Effects of Welfare Programs on Criminal Behavior: A Theoretical and Empirical Analysis. Economic Inquiry. v.35, p.120-137, 1997.

Enviado: Agosto, 2021.

Aprovado: Setembro, 2021. 